the serum can be determined. It must be remembered, however, that about $10 \%$ of pregnant women have vitamin $B_{12}$ levels of less than $100 \mu \mu \mathrm{g}$. per $100 \mathrm{ml}$. and that $25 \%$ of those who have megaloblastic changes will show similar low levels. It is evident that a full haematological investigation will be required in patients with deficiencies of both ritamin $B_{12}$ and folate.

Prophylactic folic acid therapy should be started early in pregnancy. There has been considerable argument about the requirements of normal adults and in the special conditions of pregnancy. Estimates have varied from as little as 50 $\mu \mathrm{g}$. daily ${ }^{4}$ to $500 \mu \mathrm{g}$. daily. ${ }^{5}$ D. W. Dawson and his colleagues at Manchester ${ }^{6}$ gave $15 \mathrm{mg}$. by mouth fortnightly from the 28th to the 36th week of pregnancy, and then weekly to term; Giles ${ }^{3}$ gives $5 \mathrm{mg}$. daily. This question has been re-examined by Drs. M. L. N. Willoughby and F. J. Jewell, whose conclusions are set out on page 1568 or this issue of the B.M.F. They conclude that a dose or 300 micrograms $(\mu \mathrm{g}$.) daily is the minimum dose that wiil prevent the normal fall of serum folate levels in late pregnancy. A dose of $450 \mu \mathrm{g}$. daily produces levels that are above normal, and a supplement of only $100 \mu \mathrm{g}$. daily leaves a bigh proportion of postpartum patients in the range of jefciency, with serum folate levels below $2.5 \mathrm{~m} \mu \mathrm{g} . / \mathrm{ml}$. Recent work by V. Herbert ${ }^{7}$ has shown that daily doses of solic acid of about $400 \mu \mathrm{g}$. may produce a response in patients whose megaloblastic anaemia is due to vitamin- $B_{12}$ deficiency, Ind it may therefore be undesirable to give such a dose for iong. It is fortunate that Willoughby and Jewell's suggested iaily dose appears to be in the safe range.

Prophylactic administration of folic acid has been given a zorough trial in several centres in Great Britain, Canada, and eisewhere. The results have been encouraging and there is no doubt that the incidence of megalo'blastic anaemia of pregzancy has steadily declined in the trial areas. The incidence Ji this type of anaemia is likely to be high mainly in the industrial areas, where in Britain there already exist good entenatal organizations. The administration of prophylactic iolic acid appears to have no serious difficulties and is likely to be widely adopted. But it is important to ensure that the dose of folic acid given is correct; on present findings it is $300 \mu \mathrm{g}$. daily. Willoughby and Jewell point out that there is great variation in the folic acid provided in combined iron-and-folic-acid tablets produced commercially; in these the dose varies from $50 \mu \mathrm{g}$. to as much as $15 \mathrm{mg}$.

Past experience tells us that in spite of prophylaxis some zatients will still appear with serious megaloblastic anaemia of pregnancy occurring in the last few weeks of pregnancy and the first few weeks of the puerperium. They must be treated with doses measured in milligrams. A very satisfactory response may be obtained by oral administration of 15 to $30 \mathrm{mg}$. daily. Unless there is evidence of malabsorption folic acid need not be administered parenterally. In this event $15 \mathrm{mg}$. of folic acid intramuscularly for 10 days would be sufficient.

: Chanarin, I., MacGibbon, B. M., O'Sullivan, W. J., and Mollin, D. L., Lancet, 1959, 2, 634.

- Rothman, D., and Watson-Williams, E. J., ibid., 1963, 1, 1068.

' Giles, C., f. clin. Path., 1966, 19, 1.

- Herbert, V., Arch. intern. Med., 1962, 110, 649.

- Lowenstein, L., Brunton, L., Cooper, B., Milad, A., and Hsieh, Y. S., Proc. 9th Congr. Europ. Soc. Haemat., p. 364.' 1964. Basle. - Dawson, D. W., More, J. R. S., and Aird, D. C., Lancet, 1962, 2 ,
1015. - Herbert, V., Proc. 11th Congr. int. Soc. Haemat., Plenary Session,
1966, 115.

\section{Reiter's Disease}

The triad of urethritis, arthritis, and conjunctivitis has been recognized since at least 1818 , but by one of those anomalies common in medical nomenclature takes its eponym from the description of a single case in $1916 .^{1}$

The main features are easily recognized in typical cases. Confusion sometimes arises because the syndrome may be incomplete. In fact it is so in most cases. When the signs of genital infection are inconspicuous, it is easy to fall into error. In Great Britain and in North America the disease is usually found in association with venereally transmitted urethritis, but on the continent of Europe, in Asia, and in North Africa it seems to occur more frequently as a sequel to dysentery or non-specific diarrhoea. Though gonorrhoeal arthritis does occur occasionally, the cause of this is probably another infection of unknown cause contracted at the same time as the gonorrhoea and obscured by it.

Anterior uveitis may develop during the acute stage of Reiter's disease, but more often it supervenes in the chronic stage, perhaps years after the initial infection, by which time the infection may be forgotten. The residual evidence of it remains as asymptomatic prostatitis. The acute stage of the disease may occupy from one to eighteen months or more, and the effect on the patient may vary from moderate inconvenience to prolonged, debilitating, and even dangerous illness. The attack of arthritis is usually self-limiting, and treatment can seldom do more than bring the genital infection under control and ameliorate the symptoms of systemic disease. Lesions of mucous membranes and of the skin are fairly common in the more severe attacks and may add to the patient's difficulties and unhappiness. Though there are exceptions, it seems probable that few patients who suffer from this disease make a complete and permanent recovery. Over the years there may be few or many recurrent attacks of varying severity, but always with the possibility of increasing and irreversible damage to joints. Involvement of the feet may lead to painful deformities, including pes planus, calcaneal spurs, and destruction of the metatarso-phalangeal joints, with multiple hammer toes. Sacro-iliac disease is common and may progress to atypical ankylosing spondylitis. Once established, uveitis is apt to be recurrent and may result in severe damage to sight.

Other complications of the condition, once thought to be rare, have been described more frequently since the syndrome

1 Reiter, H., Drsch. med. Wschr., 1916, 42, 1535.

2 Gamp, A., Münch. med. Wschr., 1956, 98, 334.

3 Kellgren, J. H., Ball, J., and Bier, F., Brit. med. F., 1959, 1, 527

4 Csonka, G. W., Litchfield, J. W., Oates, J. K., and Willcox, R. R., ibid., 1961, 1, 243.

5 Rodnan, G. P., Benedek, T. G., Shaver, J. A., Fennell, R. H., jun., f. Amer. med. Ass., 1964, 189, 889.

- Romanus, R., Acta med. scand. Suppl., 1953, 280, 196.

Mason, R. M., Murray, R. S., Oates, J. K., and Young, A. C., Brit. med. F., 1958, 1, 748.

8 Olhagen, B., Acta med. scand., 1960, 168, 339.

$\checkmark$ Bleehen, S. S., Everall, J. D., and Tighe, J. R., Brit. F. vener. Dis., $1966,42,88$.

10 Csonka, G., ibid., 1966, 42, 93.

11 Dienes, L., and Edsall, G., Proc. Soc. exp. Biol. (N.Y.), 1937, 36, 740.

12 Shepard, M. C., Amer. f. Syph., 1954, 38, 113.

13 Ford, D. K., and Macdonald, J., f. Bact., 1963, 85, 649.

14 Csonka, G. W., Williams, R. E. O., and Corse, J., Lancet, 1966, 1 1292 .

is Jones, B. R., Al-Hussaini, M. K., and Dunlop, E. M. C., Brit. 7. vener. Dis., 1964, 40, 19.

${ }_{16}$ Dunlop, E. M. C., et al., ibid., 1966, 42, 77.

1: - et al., 86th Annual Congress of the Ophthalmological Society of the United Kingdom, 1966, in press.

is Schachter, J., Barnes, M. G., Jones, J. P., jun., Engleman, E. P., and Meyer, K. F., Proc. Soc. exp. Biol. (N.Y.), 1966, 122, 283. 
became better known. Disease of the nervous system has been reported in both the venereally acquired and the dysenteric varieties of the disease, and usually takes the form of peripheral neuritis. Pericarditis and myocarditis with conductive defects accur in about $7 \%$ of cases in the acute stage, and aortic incompetence may develop later. ${ }^{2-5}$ Pleurisy may occur but is uncommon. The fact that some patients with Reiter's disease develop ankylosing spondylitis and that most patients with typical ankylosing spondylitis have evidence of genital infection $^{6-8}$ has led to speculation on the relationship between the two, but the matter remains unsettled. Recently S. S. Bleehen and colleagues ${ }^{9}$ described the case of a patient who died from amyloid disease of intestines, liver, spleen, adrenals, and kidneys two and a half years after the onset of a severe attack of Reiter's disease ; while in a series of 302 consecutive patients with Reiter's disease G. Csonka ${ }^{10}$ found that ten patients developed thrombophlebitis of the deep veins of the legs a few days after the onset of arthritis.

Of the many unanswered questions relating to this disease the most important is that of the cause. Reiter's disease itself has been regarded as a complication of the common condition called non-gonococcal, non-specific, or abacterial urethritis. Search for the cause of this condition has, for the most part, centred on the mycoplasma group of organisms and on viruses. But despite much work on the subject ${ }^{11-18}$ the part played by the various organisms isolated from patients remains an open question. The strong evidence in favour of venereal transmission suggests that it is an infection, and the clinical course of the disease, the cellular content of the discharge, and the response to skin tests with various microorganisms give no confirmation of the suggestion that it is an allergic process. Moreover, treatment with antihistamines and corticosteroids neither cures nor relieves the genital condition. Further advances in diagnosis and treatment await discovery of the cause, and the answer to this problem should increase our understanding of the causation of rheumatic dtseases in general.

\section{Oral Contraceptives and Tests of Thyroid Function}

There are many snags for the unwary in interpreting tests of thyroid function. It is important, therefore, that the dinician ordering such tests should be aware of factors which can give results at variance with the true thyroid status of the patient.

The most common interfering factor is exposure of the patient to iodine-containing drugs or contrast media. These block thyroid uptake of radioiodine and may raise the concentration of plasma protein-bound iodine (P.B.I.). Under normal conditions the P.B.I. is a reliable quantitative index of thyroid function, representing mainly the circulating thyroid hormone. In the euthyroid state it ranges between 3 and $7.5 \mu \mathrm{g}$. per $100 \mathrm{ml}$. plasma, varying slightly between different laboratories and methods of estimation. Figures above this level are consistent with thyrotoxicosis and below with hypothyroidism. The borderline between the normal and thyrotoxic state is less clearly defined than that between normal and hypothyroid. ${ }^{1}$
Other factors besides exogenous iodide tend to raise the P.B.I. in healthy persons and so render the test invalid as a true measure of thyroid function. It has long been known that increased levels of oestrogen in the blood, whether exogenous or, as in pregnancy, endogenous, will raise the P.B.I. to levels typical of thyrotoxicosis. This happens without any increase in uptake of radioiodine by the thyroid gland and, except in pregnancy, without a rise in the basal metabolic rate. Oestrogens do this by increasing the binding capacity of thyroxine-binding globulin for thyroid hormone. ${ }^{2}{ }^{3}$ This capacity is less for triiodothyronine than for thyroxine. The resultant increase in bound (inactive) hormone occurs without increase in concentration of free hormone; and, because thyroxine and triiodothyronine enter the cells only in free form, there are no manifestations of thyrotoxicosis. Similarly oestrogens interfere with tests of thyroid function based on uptake of radioactive triiodothyronine by the patient's red cells or by resin incubated in the patient's serum. The uptake is diminished owing to increase in the proportion of bound to unbound triiodothyronine, giving results consistent with hypothyroidism.

Among oestrogens that may affect these tests are the oral contraceptives. All of these are compounded of a progestogen and an oestrogen, each of which may vary in structure and quantity as between different preparations now in use. Progestogens seem to have little if any effect on P.B.I. or other tests of thyroid function, so it can be assumed that any such action of these pills is due to the oestrogen component. It has been reported that in women taking oral contraceptives containing $0.05 \mathrm{mg}$. ethinyl oestradiol there is no increase in P.B.I. ${ }^{4}$ However, when the dose of ethinyl oestradiol is 0.075 mg. ${ }^{5}{ }^{6}$ or of ethinodiol diacetate $1 \mathrm{mg} .{ }^{7}$ or of mestranol $0.075-$ $0.1 \mathrm{mg} .{ }^{8}$ all reports have shown an increase in P.B.I. in a large proportion of women.

Recently D. Winikoff and K. Taylor ${ }^{9}$ have studied the short- and long-term effects of a wide variety of oral contraceptives on various indices of thyroid function. They found that each of ten different preparations caused an increase in P.B.I. and a fall in the uptake of radioactive triiodothyronine by resin. Thyroid uptake of radioiodine at four hours was unaltered. The changes were proportional to the quantity of oestrogen in the preparations used. After one cycle of administration the changes continued for three to seven days, with return to normal four weeks after cessation of treatment. During long-term administration the effects were slightly greater, and return to normal took at least six weeks after the woman ceased taking the contraceptive pills. The magnitude of these changes, though not nearly so great as in pregnancy, were sufficient to bring many of the test results into the thyrotoxic range.

Thus in women of child-bearing age undergoing tests of thyroid function it is essential to know whether they are taking oral contraceptives. When they are, radioiodine uptake by the thyroid gland is the most reliable test.

Radcliff, F. J., Baker, J. M., Croydon, M. J., Hart, M. J., and Hales, I. B., 7. clin. Endocr., 1964, 24, 883.

2 Dowling, J. T., Freinkel, N., and Ingbar, S. H., ibid., 1956, 16, 1491 .

3 Tata, J. R., Brit. med. Bull., 1960, 16, 142.

Walser, H. C., Margulis, R. R., and Ladd, J. E., Int. F. Fertil., 1964, 9, 189.

5 Hollander, C. S., Garcia, A. M., Sturgis, S. H., and Selenkow, H. A., New Engl. F. Med., 1963, 269, 501.

- Larsson-Cohn U., Lancet, 1965, 1, 317.

' Pincus, G., Searle Symposium, 1964. Melbourne.

${ }^{8}$ Florsheim, W. H., and Faircloth, M. A., Proc. Soc. exp. Biol. (N.Y.), $1964,117,56$.

'Winikoff, D., and Taylor, K., Med. F. Aust., 1966, 2, 108. 